\title{
As novas identidades políticas da sociedade digital
}

\section{Rodrigo Saturnino}

Doutor em Sociologia pelo Instituto de Ciências Sociais da Universidade de Lisboa (ICS-UL), investigador colaborador do Centro de Estudos das Migrações e das Relações Interculturais da Universidade Aberta (CEMRI-UAB) e bolsista da Fundação para Ciências e Tecnologia (FCT).

E-mail: rodrigo.saturnino@gmail.com
Resumo: $\mathrm{O}$ artigo analisa as ações afirmativas dos Partidos Piratas a fim de compreender como o seu discurso se move na tentativa de reordenar o olhar e os sentidos normativos acerca da pirataria para, dessa forma, fortalecer as suas teses e afirmar uma nova identidade política. Ainda no campo analítico, o texto demonstra a conversão criativa que realizaram ao apoiarem-se, de modo homônimo, na desconstrução de uma categoria social admitida historicamente como marcador arbitrário. Argumenta-se que a ação inicial dos piratas utiliza a acusação como recurso operatório, transformando-a em benefício publicitário para a ação política que promovem. A análise, de cariz qualitativa, foi baseada em documentos oficiais, no material de propaganda e em entrevistas realizadas com membros da Alemanha, Brasil, Portugal e Suécia.

Palavras-chave: Identidades políticas; Internet; Partido pirata; Pirataria; Propaganda.

\section{Title: New political identities in digital society}

Abstract: This article analyses the affirmative action detected in the Pirate Parties in order to understand how their speech moves in attempt to reorder the normative meanings about the piracy to reinforce their theses and to affirm a new political identity. The work demonstrates the creative conversion performed to deconstruct a social category historically admitted as an arbitrary stigma. It argues that the first action of the pirates seeks to use the accusation as an operative source, transforming it in a benefit advertiser to promote their political action. The qualitative analysis was based on official documents, propaganda material and interviews with members of Brazil, Germany, Portugal and Sweden.

Keywords: Political identities; Internet; Pirate party; Piracy; Propaganda. 


\section{Introdução}

Recentes pesquisas e relatórios no campo das Ciências Sociais têm dedicado uma significativa atenção sobre os conflitos entre o mercado e a pirataria no contexto da informação digital (VAIDHYANATHAN, 2003; STRANGELOVE, 2005; GANTZ; ROCHESTER, 2005; LESSIG, 2008, 2004; JOHNS, 2009; MASON, 2009; KERNFELD, 2011; HIGGINS; MARCUM, 2011; DECHERNEY, 2012; CASTELLS; CARDOSO, 2013; BELISÁRIO; TARIN, 2013). Nesses estudos é comum encontrar acepções conjunturais sobre os impactos e os efeitos dessas práticas sociais em relação à produção, à circulação e à distribuição de bens e serviços. Tais hipóteses, baseadas no interesse, na racionalidade e na utilidade, podem ser divididas em, pelo menos, três perspectivas: 1 ) aquela que entende a pirataria como responsável pelo atraso no crescimento econômico; 2 ) outra que questiona a impossibilidade da mercadorização da informação; e 3) a que justifica os benefícios da livre circulação dos bens informacionais (dados informáticos, músicas, filmes, jogos, livros, patentes, softwares) como um fator essencial para capacitar as pessoas e para criar novos modelos de negócio. O fenômeno, já muito bem detalhado nesses estudos, deve-se, principalmente, à digitalização da informação e ao barateamento dos artefatos tecnológicos. Acima de tudo, as divergências foram acentuadas devido à facilidade de reprodução e circulação da informação digital e às dificuldades de excluir os terceiros desses processos.

Apesar das diversas perspectivas acerca da pirataria, tal prática, levando em conta o percurso histórico pela qual foi socialmente construída, é considerada um crime de violação do monopólio nas suas variadas instâncias. Nos casos que envolvem a informação, atinge especificamente a ideia da propriedade intelectual (SCHWEIDLER; COSTANZA-CHOCK, 2005; JOHNS, 2009). Geralmente, o argumento dos que defendem a antipartilha é resumido pela alegação de que a prática subtrai dos autores o direito de desfrutar financeiramente do seu trabalho por não receberem o que lhe é devido através deste tipo de consumo. Esta retração interpretativa tem sido fortemente questionada. Quem a critica ressalta que a inoperância dos aparelhos jurídicos, na tentativa de suprir o que Boyle (2008) denominou "falha" no mercado digital, visivelmente tem privilegiado não só o interesse empresarial na privatização da informação, como tem utilizado o próprio recurso legal, baseado na gênesis da propriedade privada, para justificar a criação de políticas de incriminação, monitoramento e vigilância dos utilizadores da internet. Nessa perspectiva, alguns autores defendem que, na maioria dos casos em que a questão vem à tona, a acusação recai sobre o consumidor porque falta na legislação internacional indiferenciações específicas acerca da circulação da informação digital no nível das interações privadas, independentemente de serem definidas pelo dinheiro ou não (LEMOS, 2005; LESSIG, 2008; 2004; POSTIGO, 2012).

Por sua vez, a ausência de ordenamentos jurídicos compatíveis com a realidade, por exemplo, da arquitetura da internet, e a consequente mudança na ética dos utilizadores têm intensificado o conflito de direitos entre proprietários e consumidores. Ou seja, a comercialização da informação enquanto bem submisso à lógica capitalista da propriedade privada não estabelece uma dialética coerente com a ideia clássica de mercadoria, já que apenas concede usufruto limitado ao consumidor/comprador. Por outro lado, quando encontramos tentativas de diferenciações, não são consideradas, em boa parte dos estudos, como práticas legitimadas. São, dessa forma, categorizadas como instrumento de lobby econômico de empresas interessadas no aumento dos fluxos de dados informáticos e no consumo de seus produtos.

As ambiguidades continuam. Além das medidas coercitivas e legais disponíveis para o combate à pirataria digital, outro recurso utilizado para justificar a caça aos piratas tem se afirmado pela arbitrariedade da propaganda. A estratégia 
complementa o discurso da imoralidade da cópia não autorizada ao apoiar-se em intensas campanhas educativas pulverizadas pela grande mídia, elaboradas a partir da sua associação com a imagem mítica e marginal dos piratas marítimos, a qual foi desfiguradamente socializada pelo viés do roubo e do crime. Nesse sentido, a estratégia de marketing da indústria baseada nas leis do copyright e, por conseguinte, a influência que exercem sobre o ordenamento jurídico internacional, orquestra o imaginário popular acerca dos riscos da pirataria, transformando a opinião pública em parceira com a iniciativa privada no processo de exigência do fortalecimento das medidas legais reparatórias.

As fronteiras de simplificação da pirataria como delito e prática desviante também têm sido contestadas por meio de novas abordagens e novos movimentos sociais, que lutam pela reordenação do campo semântico da lei em relação ao capitalismo informacional (CASTELLS, 2007; SCHILLER, 1999). Tais fenômenos, como o movimento dos hackers, Software Livre, Creative Commons, Copyleft, Wikileaks, do ativismo de Julian Assange, Eduard Snowden e Chelsea Manning (Bradley) e, finalmente, dos Partidos Piratas, parecem instaurar um esboço de negação das relações monopolistas e territoriais da informação (VERGNE, 2013; STALLMAN, 2002; GORZ, 2005). Esses grupos sociais, que Durand e Vergne (2013) denominaram organizações piratas, interpretam a pirataria não apenas como um problema econômico, mas principalmente como uma questão mal resolvida da geopolítica internacional.

Perante o quadro apresentado, neste capítulo optei por salientar algumas ações afirmativas do Movimento dos Partidos Piratas, doravante designado de MPP, a fim de compreender como o seu discurso se move na tentativa de reordenar o olhar e os sentidos normativos sobre a pirataria para, assim, fortalecer as suas teses e afirmar uma nova identidade política. Metodologicamente, o texto foi elaborado a partir de uma análise qualitativa baseada em documentos oficiais, em algumas peças de propaganda e em uma fração do material recolhido em entrevistas realizadas com membros do Partido Pirata da Alemanha, Brasil, Portugal e Suécia entre os anos de 2012 e 2013. Embora existam diferenças entre tais partidos, principalmente no âmbito da sua oficialização como instituição partidária, como é o caso do Brasil e de Portugal, vale ressaltar que essas circunstâncias não implicaram a diminuição analítica do objeto em estudo. Em linhas gerais, o principal intuito deste trabalho é demonstrar a conversão criativa realizada pelo MPP ao apoiar-se, de modo homônimo, na desconstrução de uma categoria social que tem sido admitida historicamente como marcador arbitrário do crime. Acima de tudo, argumenta-se que a ação inicial do MPP procura transformar a acusação em recurso operatório para ressignificar a propaganda do inimigo, transformando-a em benefício midiático para a ação política que promove.

\section{A pirataria como problema geopolítico: das águas neutras para a rede descentralizada}

Desde os tempos de ouro da pirataria marítima, quando não existia ainda regulamentação territorial do mar, as disputas entre impérios impediam a criação de uma perspectiva legal para estabelecer um marco conceitual sobre a questão. O conceito da pirataria, desde 1700 , permanece obscurecido pela sua indecisa aplicação, e tem servido como recurso variável para identificar a violação do direito soberano do Estado ou dos comerciantes sobre suas propriedades através da invasão de suas rotas marítimas. O maior problema da designação da pirataria marítima era definir os limites territoriais do alto mar entre um império e outro. A ausência de acordos entre os governos era propícia para a constante mudança de perspectiva a respeito do termo. As disputas pelo monopólio das rotas comerciais entre portugueses, espanhóis, holandeses e britânicos evidenciam, no rastro histórico do conceito, como o assunto se manteve mergulhado em ondas de ambiguidades retóricas, servindo ao interesse expansionista e ao domínio 
econômico das rotas ultramarinas a fim de manter as soberanias imperiais. Assim, buscando superar a concorrência, chamar alguém de pirata, como fizeram os mercadores portugueses na era moderna na tentativa de reivindicar os direitos de propriedade e proteger o caminho marítimo para as Índias, servia de pressuposto legal para justificar o uso de qualquer meio para afastar os adversários do negócio (DURAND; VERGNE, 2013). Nesta ordem de pensamento, é possível admitir que a pirataria marítima foi instituída para resolver um problema geopolítico em que a batalha pela expansão das fronteiras de dominação comercial era evidente. Em termos gerais, a pirataria marítima envolvia um problema que dizia respeito não apenas ao roubo do que os navios transportavam, mas, também, à violação do privilégio sobre o meio de circulação de mercadorias.

O debate sobre a pirataria é transbordante. $\mathrm{O}$ conflito entre os que defendem a equiparação do mar ao território continental e, portanto, apto a ser delimitado, e a visão daqueles que o advogam como espaço de liberdade passou a reverberar em novos campos de dominação política e econômica. Estes espaços preservaram não só as lutas de interesses como também importaram para si boa parte das metáforas que eram atribuídas à pirataria marítima.

A pirataria foi transportada do mar para o universo editorial já a partir do século $\mathrm{XVI}$ - quando as leis dos venezianos e dos ingleses concederam monopólios de impressão a editores específicos e estabeleceram o controle do Estado sendo utilizada, também, para designar os editores que faziam impressões sem autorização dos autores ou sem pagamento pelo direito de exploração da obra (JOHNS, 2009; SCHWEIDLER; COSTANZA-CHOCK, 2005). Adiante, já no século XX, o caso do monopólio das ondas sonoras da rádio e do espectro eletromagnético voltou a ser tema recorrente da pirataria quando a Coroa Inglesa, em 1920, garantiu o privilégio da British Broadcasting Corporation (BBC) para impedir transmissões alternativas. $O$ resultado foi previsível e as rádios piratas se multiplicaram. Em 1967, depois da BBC perder a exclusividade, as ondas sonoras passaram a ser admitidas pelo governo britânico como um bem público (VERGNE, 2013).

No mesmo itinerário, a regulação do ciberespaço foi incluída nas conexões da pirataria a partir das tensões originadas pelo interesse de gigantes das telecomunicações, como a American Telephone and Telegraph Company (AT\&T), em expandir o seu domínio comercial. A reorganização do mercado na década de 1960 nos Estados Unidos demonstra como a evolução das tecnologias de difusão e distribuição de informação, a partir de computadores interligados em redes digitais, estabeleceu um novo campo de disputa entre os consumidores, o governo e as corporações. A política neoliberal de desregulamentação do mercado das telecomunicações fortaleceu não só o capitalismo tradicional através da criação de uma nova versão para o lucro, como também colocou em questão os projetos tecnocientíficos baseados na arquitetura da internet (SCHILLER, 1999). Os privilégios comerciais e a proteção intensiva dos bens informacionais que emergiram desse novo mercado pelo reforço técnico e legal dos direitos autorais salientaram, entre outras coisas, a fragilidade de temas valiosos aos humanistas, como o direito à privacidade, à liberdade de expressão e à luta contra a privatização do bem público. As diversas investidas de controle da circulação desses bens, laureadas por acordos internacionais (leia-se as ações da NSA - National Security Agency e projetos de parcerias público-privadas de vigilância social, como o PRISM, ACTA, SOPA) reafirmam a gravidade dos conflitos que emergiram no cenário digital, ocasionados pelas rupturas do monopólio da informação.

O tema não termina aqui. Fora do contexto tecnológico, a pirataria também foi alvo do campo da informação genética, das grifes e das invenções. A biopirataria, a violação das patentes e a contrafação de artigos de marcas de luxo integram o extenso panorama em que o tema da pirataria está submerso. Em resumo, pode-se admitir que a pirataria é uma questão de perspectiva, sendo invocada 
em todos os casos em que o monopólio das formas capitalistas de distribuição e de acesso, nas suas diversas instâncias, sofre alguma ameaça. Nesse sentido, a desorganização que se estabeleceu no ordenamento jurídico internacional sobre o controle das diversas formas de pirataria tem reforçado certa impertinência política na formulação de leis harmonizadoras dos conflitos entre o interesse privado na comercialização de conteúdos e o interesse público em sua livre utilização, seja pela compra dos mesmos ou pela sua circulação e partilha em lugares neutros, como o mar, a internet, o etéreo ou o espaço sideral. Dessa forma, a pirataria também é paradigmática para a lei, servindo de pressuposto para cimentar práticas de vigilância, controle e punição de qualquer evasividade que ultrapasse a constituição de direitos sobre a circulação de bens em espaços sem regulação. Como definir fronteiras e leis internacionais em espaços imaginários? Como prover garantias aos capitalistas para que suas mercadorias (em qualquer formato e acepção) sejam preservadas e comercializadas sem interferências nos lugares de ninguém? Seria incrementando as políticas de controle e os processos de incriminação civil? Reforçando a moral do direito à propriedade privada em todos os seus segmentos?

No interlúdio dessa desorganização política e dos conflitos internacionais originados pela (in)definição da pirataria, o primeiro Partido Pirata foi formado na Suécia na tentativa de oferecer uma perspectiva elaborada não mais pelas vozes dos acusadores, mas pelos próprios acusados. Como veremos a seguir, a proposta inicial dos piratas suecos foi incentivada pela intensa campanha de perseguição levada a cabo pela parceria público-privada na tentativa de conservar o monopólio da propriedade intelectual.

\section{O código-fonte: da Suécia para o mundo}

O primeiro Partido Pirata surgiu na Suécia (Piratpartiet) em 2006 e foi impulsionado por duas situações ocorridas em 2003: 1) a criação da Swedish Anti-piracy Bureau (Svenka Antipiratbyrån), uma agência privada financiada pela Motion Picture Association of America (MPAA) destinada a salvaguardar a aplicação da lei de direitos autorais no país; e 2) o surgimento do Piratbyrån, um coletivo marcadamente disposto a incluir o debate sobre o copyright na agenda pública a fim de transformá-lo em um problema político (MIEGEL; OLSSON, 2008). O conflito foi reforçado depois que o ministro Thomas Bodström, em 2005, levou a público um projeto de lei para intensificar as medidas de fiscalização e monitoramento da internet, apoiado na promessa de garantir maior segurança à sociedade sueca.

Aproveitando as ameaças políticas concentradas em torno da internet, o informático Rick Falkvinge criou, no dia 01 de Janeiro de 2006, o protótipo do

${ }^{1}$ Direct Connect é uma rede de partilha de ficheiros e de canais de bate-papo on-line.

${ }^{2}$ Tracker é o nome que se dá a um servidor que rastreia computadores de utilizadores que possuem determinados arquivos. que seria o website do partido através de um hub na rede Direct Connect ${ }^{1}$. Nos dias seguintes, a página na internet recebeu milhares de visitas. Falkvinge largou o trabalho, fez um empréstimo bancário e decidiu dedicar-se integralmente à construção do partido. No intercurso da sua criação, o ataque irruptivo da polícia sueca aos servidores do The Pirate Bay, um tracker ${ }^{2}$ criado pelo Piratbyrån para experimentar a partilha de ficheiros indexados em websites utilizando a tecnologia das redes peer-to-peer (P2P), resultou no aumento da popularidade do Piratpartiet. No entanto, a adesão de milhares de novos membros não significou votos suficientes para vencer a primeira eleição. Na disputa nacional de 2006, obteve $0,63 \%$ dos votos. Mesmo sem resultados favoráveis, sendo o mínimo para garantir um lugar no Riksdag (Assembleia Parlamentar da Suécia) equivalente a 4\%, o Partido tornou-se o terceiro maior fora do Parlamento, ultrapassando, por exemplo, o Partido Verde Sueco (LI, 2009; ERLINGSSON; PERSSON, 2011). Nas eleições para o Parlamento Europeu de 2009, o Piratpartiet recebeu 7,13\% do total de votos da Suécia e garantiu um assento parlamentar.

Quando foi criado, o alvo principal do Partido Pirata era conduzir o copyright para o debate político, questionando as origens e formas de legitimidade que o setor 
privado dispunha para monopolizar a informação e restringir a autonomia civil de partilhar livremente em âmbito privado e sem fins comerciais, utilizando, por exemplo, as redes P2P. Dessa forma, o Piratpartiet passou a enfatizar a releitura de conceitos cruciais para a organização estrutural e a legitimação do copyright - como o de autoria e o de propriedade intelectual - à luz do desenvolvimento tecnológico e da afirmação de princípios morais baseados em valores pósmaterialistas (MIEGEL; OLSSON, 2008).

A aparente política restritiva que definia seu projeto inicial foi alvo de inúmeras críticas. Em Julho de 2012, ainda era possível ler no site dos suecos: "o Partido Pirata tem apenas três questões em sua agenda: 1) Reformar a lei do copyright [...] ; 2) Abolir o sistema de patentes [...] 3) Respeitar o direito à privacidade" (PIRATPARTIET, s.d., s. p.). A base de sua fundação se manteve, entretanto o discurso radical passou a ser moderado. As teses políticas adquiriram maior robustez ideológica, atingindo um campo social mais expressivo. As limitações do primeiro projeto foram superadas por meio da adoção de princípios mais abrangentes. O novo layout programático que hoje encontramos no Piratpartiet é fruto de uma "evolução organizativa" (PANEBIANCO, 2005) integrada por três períodos distintos: a primeira fase foi marcada por um protesto inicial; a segunda, pela formação de uma plataforma específica para atender as queixas que não estavam contempladas nas propostas dos partidos tradicionais; e, por fim, a terceira, assinalada pela elaboração de propostas mais robustas e capazes de suportar um quadro extenso de ação.

Atualmente, o número de países a levantarem a bandeira pelos próprios partidos (oficializados e em processo de oficialização) já passa dos sessenta. A rapidez do seu alastramento fortaleceu o MPP como um dos mais importantes fenômenos sociais do século XXI. A eleição de dois euro-deputados, em 2009, pelo Partido Pirata da Suécia, a ascensão fulminante do Partido Pirata da Alemanha em 2012 e o desempenho dos piratas da Islândia são indícios singulares da sua gradativa penetração no espectro político. Ao contrário do que alguns analistas consideraram como um efeito da insatisfação do eleitorado com a política nacional, na análise de Erlingsson e Persson (2011) a vitória do Piratpartiet em 2009 foi um triunfo estabelecido por meio da identificação individual dos eleitores com as premissas do Partido, bem como da constatação da ausência desses princípios nas propostas dos políticos tradicionais. Na conclusão dos autores, a principal razão que explicaria o seu sucesso inicial deve-se ao fato do Partido Pirata ter sido o único a representar o ponto de vista dos eleitores em questões relacionadas ao direito à privacidade e ao download pela internet (ERLINGSSON; PERSSON, 2011).

Além dos três princípios basilares, a política comum dos piratas passou a privilegiar mais dois: a transparência da gestão pública e a construção de uma nova democracia. A dilatação das ações programáticas recebeu impulso por meio da acolhida realizada pelo MPP às potencialidades instrumentais das tecnologias digitais na promoção de uma experiência efetiva do exercício político. Dessa forma, passou a defender propostas conjuntas orientadas pela promoção do livre acesso às informações de atos públicos a fim de permitir a fiscalização e a abertura pública de todos os processos que envolvam o Estado. Como último objetivo e talvez o mais obstinado, o MPP incluiu o compromisso de buscar novas formas para constituir uma democracia definitivamente deliberativa.

Nos países que seguiram o exemplo da Suécia, os princípios iniciais mantiveramse resguardados. Todavia, as propostas passaram a obedecer a uma lógica de caráter holístico de acordo com os diferentes contextos culturais. Embora os partidos subsistam com dinâmicas distintivas, a solidariedade política transnacional tem sido reforçada, seja pela criação de organizações internacionais como o Partido Pirata Internacional, criado em 2010 para estabelecer uma rede imaginária racionalmente disposta a colocar em prática o seu caráter comunitário 
na luta pelos objetivos comuns, ou pelo alinhamento ideológico das formas de encenação social que integram a sua marca identitária coletiva.

\section{"Podem me chamar de pirata": processos simbólicos de identificação e construção do imaginário}

Dentre as formas simbólicas utilizadas pelos piratas para agregar valor social a sua imagem institucional, destaca-se a tentativa de requalificação e deslocamento semântico presentificado no próprio nome do movimento. O exercício é premeditado, funciona como uma âncora retórica para assegurar a sua imagem não pela via do crime, mas pelo confronto e ruptura com os sentidos normativos e as perspectivas que categorizam as práticas sociais defendidas por estes atores.

Em linhas gerais, o exame do Movimento revela o hibridismo da sua ação: mudar radicalmente a forma de se fazer política, a começar pelo impacto expressivo que realizam na formulação da suas teses e na elaboração da sua marca identitária enquanto presença contrastante dos protocolos tradicionais, nem que o campo da política é entendido como espaço sério da ação formal. A abordagem programática, o marketing do nome do Partido e a héxis linguística e corporal que utilizam indiciam o esforço dos piratas em reorientar a narrativa e a gramática da política.

Ao transportarem o protótipo do pirata para o campo da política, parecem reafirmar a função da linguagem na batalha pela produção de sentidos. O nome é o primeiro símbolo neste campo de disputa. Representa para um partido político uma denominação distintiva e, sobretudo, o próprio programa e a bandeira pela qual lutam (DOMENACH, 1963). Nesta rota, o jogo social e a determinação dos sentidos dependem da posição objetivada que o sujeito assume perante o significado anteriormente concebido.

Conforme salientou Bourdieu (1989), o sentido, enquanto recurso discursivo, exerce um poder simbólico sobre as identidades devido ao seu caráter de "estrutura estruturante". Este mesmo sentido depende da condição ideológica em que foi criado. Entretanto, o enunciado não sobrevive autonomamente. Sua vida depende da cumplicidade daqueles que se submetem e daqueles que exercem o poder através da sua força social. Assim, a produção de sentido sentencia uma disputa ideológica e constante no interior de todas as relações de poder:

somos piratas porque somos contra a lei que diz que somos piratas [...]. Trabalhar com seriedade é o caminho para mostrar que criminosas são as leis que dizem que nós somos criminosos. [...] o que nós fizemos com muito bom humor foi nos apropriar desse apelido. Querem me chamar de pirata, podem me chamar de pirata. É uma estratégia de comunicação, uma sacada de marketing. Pelo crescimento da causa no mundo, dá pra ver que está funcionando (Entrevista colaborativa com membros do Partido Pirata do Brasil) ${ }^{3}$

${ }^{3}$ Entrevista realizada via software Etherpad (editor de textos para escrita coletiva em tempo real) entre os dias 08 e 13 de Agosto de 2012.
Para Bourdieu, ao partilhar o pensamento do linguista dinamarquês Louis Hjelmslev, "os signos [...] não são definidos positivamente por seu conteúdo, mas sim negativamente através do contraste da sua relação com os demais termos do sistema" (HJELMSLEV, 1959 apud BOURDIEU, 2009, p. 17). Dessa forma, já que se apresentam como aquilo que o outro supostamente não deveria ser, os signos atribuem valor simbólico contrastante dentro da estrutura social - questão pertinente também aos estudos de Goffman (1988) sobre o estigma e os de Becker (2008) e Pollner (1987) sobre o desvio. Esse exercício é predisposto por um tipo "de harmonia preestabelecida a exprimir o nível estatutário que, como a própria palavra indica, deve o essencial de seu valor à sua posição em uma estrutura social definida como sistema de posições e oposições" (BOURDIEU, 2009 , p. 17). Tal processo é animado pela elaboração de categorias homólogas 
e opostas a fim de estabelecer os marcos entre aquilo que é desviante e diferencial. Essa estratégia foi considerada pelo sociólogo como um apriorismo ocupado em determinar o sistema de significações a partir do jogo da associação e da dissociação; da inclusão e da exclusão no interior das estruturas sociais, "arrancando os elementos constitutivos desta estrutura, grupos ou indivíduos, da insignificância" (BOURDIEU, 2009, p. 17, sublinhado do autor).

Importante registrar que, nos seus interlúdios, o pirata também foi estilizado na literatura e por grupos dissidentes de modo divergente e polissêmico como um símbolo de resistência heroica. Contudo, a estratégia enunciativa não adquiriu força social suficiente para romper com seu estado homossemântico. De certa forma, a utilização discordante da palavra e a autorreferenciação como exercício simbólico de ruptura, apesar de representar uma aparente atitude subversiva que se opõe ao sentido ideológico e estruturante da categoria, pode também contribuir para reforçar a qualidade sujeitada do que se nomeia à estrutura da linguagem distintiva. Todavia, a "colagem" do termo à identidade que se pretende mostrase vigorosamente defendida pelos atores na forma de uma objeção heterotópica apoiada, de modo reflexivo, nas atitudes que caracterizam o ser mítico do pirata, que nesse caso específico refere-se à destruição das miragens sociais elaboradas pelos monopólios semânticos.

Seguindo esse raciocínio, também encontramos no caráter contrastante do MPP aquilo que Goffman (1988) defendeu a respeito das variações intermitentes que sofre o processo de estigmatização. Como elemento construído e/ou legitimado pelos atores sociais, o estigma permite a sua inversão. Da mesma forma que pode ser estabelecido e "colado" na personalidade de um indivíduo ou na ação de um grupo, também pode ser modificado sem ser, necessariamente, desvinculado (LIMA, 2001). A inversão de papéis, onde o rotulado torna-se rotulador, é possível, seguindo a sugestão de Goffman (1988), porque o processo de estigmatização fundamenta-se nas interações simbólicas e não na concretude dos sujeitos. Nesse caso, o que determina a condição estigmatizante é a força da representação existente ou não no contexto das diferentes relações e na variedade de grupos nos quais o indivíduo estigmatizado interage (SCHILLING; MIYASHIRO, 2008). Assim, o estigma deve ser considerado como "perspectivas geradas nas situações sociais interativas de normas não cumpridas", em que todos os sujeitos integram a mesma complexidade social (GOFFMAN, 1988, p. 137).

\section{Perna de pau, olho de vidro e cara de mau: a bricolage e a performatividade como recursos de confronto}

Os processos metonímicos e o modo quase artesanal de afirmação da política do MPP também podem ser entendidos pela ideia de bricolage. Para Lévi-Strauss (2003), ao ressignificar ao conceito na tentativa de explicar as diferenças entre o pensamento mítico e o científico, o bricoleur trabalha com os "meio-limites", isto é, um conjunto contínuo e restrito de utensílios e materiais. Isso significa que o bricoleur utiliza os recursos que tem em mãos para elaborar estratégias evasivas no sentido de dar origem a novos resultados e artefatos. A sua lógica não só contrasta a formalidade do arquiteto e do engenheiro, como também opõe-se à forma organizacional que a compõe. O bricoleur é um artista do improviso e, na falta do previsto, desenvolve mecanismos criativos e particulares de afirmação da sua obra autônoma.

Floch (1995) também buscou identificar formas de bricolagem na produção das identidades visuais. Utilizando a ideia preliminar de Lévi-Strauss (2003), defendeu que a identidade como forma expressa a partir de uma práxis enunciativa é formada por um processo bricolar, em que as formas fixas são utilizadas para criar o novo a partir do antigo. Isso equivale a dizer que toda ação de bricolage implica a presença de um sujeito enunciador que constrói, de modo particular e contrária à erosão do sentido, contra a désémantisation, a própria identidade através de um 
ato de libertador (FLOCH, 1995). Assim, a bricolagem é uma prática fragmentária, periférica e rizomática que utiliza o contorno como uma atividade - mesmo não sendo planificada desde o início da ação -, de reorganização empírica a partir de elementos desprezados e descartados pela suposta ordem, tornando-se um recurso intenso para a desestabilização. A partir do seu uso, o tom depreciativo do adversário endossa a transformação da acusação em uma epígrafe de grandeza (DOMENACH, 1963, p. 34). Nessa ótica, o eufemismo do MPP converge a sua prática por meio do caráter liberador que a bricolagem providencia. Oporse à uniformização das identidades e dos protocolos de representação do mundo significa revitalizar a imagem do pirata como marcador performativo contra a acusação adjetivada da política que defende. Esta conversão se espalha por toda a dinâmica interativa dos atores. Não bastasse a utilização renitente do epíteto, os piratas resgatam o universo da pirataria marítima a partir de encenações teatrais a fim de abonar uma identidade exclusiva. Um "Ahoy!" é, muitas vezes, invocado para saudar uns aos outros e um "Arrr!" para assinalar uma exclamação (Figura 1).

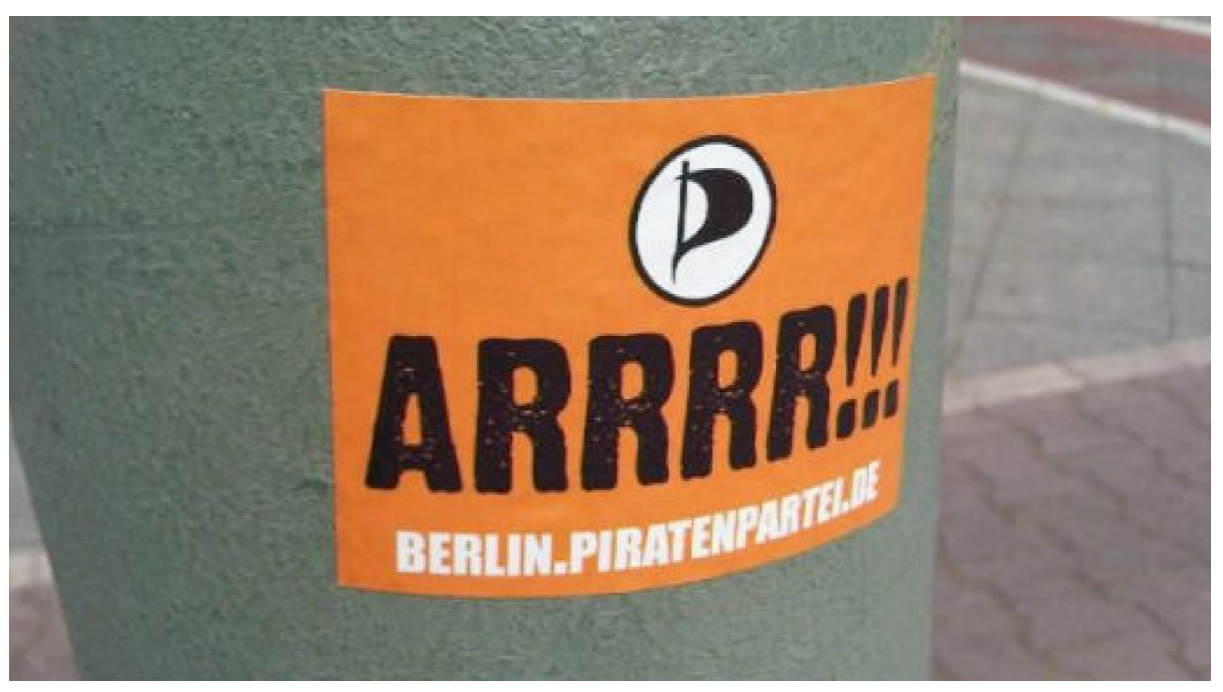

Figura 1: Publicidade - Piratas de Berlim/Divulgação (TORRENT FREAK, 2011)

As referências marítimas não param. Também estão presentes no símbolo internacional do Partido: uma vela de um barco forma a letra " $p$ " em cores monocromáticas, fortalecendo o imaginário dos atores ao criar uma conexão figurativa com a famosa bandeira de Jolly Roger (Figura 2). A simplicidade do símbolo gráfico colabora com a integração cômoda do MPP ao invocar um conjunto de ideias e sentimentos intercambiáveis pela unidade ideológica de suas principais propostas. Como defendeu Domenach (1963), as fórmulas claras e a redução do tom rebuscado e abstrato das propagandas partidárias parecem favorecer resultados no processo elementar de fixação de uma ideologia. Essa identificação quase automática dos piratas com o preto e o branco é fruto da história das suas aventuras. São construções conotativas que transgridem artificialmente a norma (DURAND, 1974). De acordo com Machado (2013, p. 37), esse modo de agir "intriga pela sua inevitável associação com a dualidade de diversos sistemas de crenças que, a sua maneira, tentam decompor ou desconstruir a realidade em seus níveis mais básicos".

${ }^{4}$ A logomarca do Partido Pirata, desenhada por Marie "Emma" Andersson, está em domínio público. Segundo a informação do Wikipedia, a imagem não contém nenhum direito autoral, ou seja, sua utilização é livre e não é necessária autorização para qualquer tipo de uso, apenas a citação do autor, quando for o caso. As imagens sem crédito neste texto seguem o mesmo princípio.

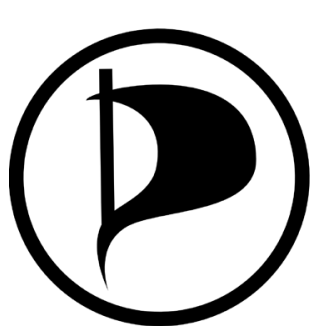

Figura 2: Logomarca do Partido Pirata /Divulgação (WIKIPEDIA, s.d.). ${ }^{4}$ 
Como pronome de tratamento, o pirata abandona o seu caráter adjetivado e passa a denotar um substantivo que pretende identificar não só uma nova classe de políticos, mas um novo estilo de vida. Essa ampliação interpretativa através da positivação da terminologia aspira favorecer o contágio social na medida que os atores utilizam as mitologias dos piratas como símbolos de resistência. Assim, convergem a sua ação por meio de exercícios exaustivos de elaboração de recursos discursivos empáticos a fim de amplificar a perspectiva que defendem. Esta conversão é, de modo ofensivo, fundamentada em discursos humanistas que se opõem a ameaças contra direitos fundamentais.

Incorporar o pirata é uma tática híbrida. No campo partidário, nasce como nova categoria política. No campo social, afirma-se para assegurar uma ideologia contra monopólios. Assim, racionalizar e reconstruir a identidade do pirata ampliando afirmativas parece funcionar como uma extensão do horizonte de aplicação de uma perspectiva autônoma, seja na formação das próprias teses políticas ou na autonegociação com as implicações sociais que a ideologia solicita.

Do mesmo modo, essa amplitude, integrante do quadro evolutivo das premissas fundacionais do MPP, pretende criar um fluxo contínuo de penetração social. Quanto mais a categoria é reorientada para distinguir causas políticas, mais ela atingirá indivíduos simpatizantes com os princípios tutelados pelos piratas:

${ }^{5}$ Entrevista realizada através da aplicação de inquéritos utilizando o software LimeSurvey. $O$ inquérito foi aplicado a membros dos Partidos Pirata entre os meses de Dezembro de 2012 a Outubro de 2013. Os entrevistados tinham a liberdade de manter o anonimato, mas era mandatório identificar o país e confirmar o envolvimento direto no Partido Pirata local. Nos casos utilizados neste texto, os atores optaram por identificar apenas o país de origem. As falas foram recolhidas através da aplicação guias de entrevistas e fazem parte do material de análise da minha tese de doutoramento. Por este motivo, o conteúdo integral não está disponível publicamente

${ }^{6}$ Depoimento recolhido em conversas informais por bate-papo on-line com membros do Movimento do Partido Pirata Português, via chat do gmail (correio eletrônico) e do Facebook, em diferentes dias do mês de Dezembro de 2012.

${ }^{7}$ Cf. nota 6 deste capítulo.

${ }^{8} \mathrm{Cf}$. nota 6 deste capítulo.
Para mim, ser pirata envolve mais do que uma posição política; é uma visão de mundo. Se os piratas defendem a disseminação do conhecimento e a democracia direta, por exemplo, uma pessoa que lê para as crianças de um orfanato, ou um pai que ensina seus filhos sobre as mazelas da política e dos políticos, são piratas, sem saber! [...] (Brasileiro, masculino, 42 anos, inquérito) ${ }^{5}$

[Todo mundo é pirata?] Depende do ponto de vista [...] mas sim se pensares desde os livres pensadores até aos que hoje sacam na net, todos são piratas. Mas também depende da conotação que se dá ao significado de pirata. 0 problema é que pirata tem muitos significados bons e maus [...]. Pirata pode ser um hacker, uma pessoa que faz downloads, um ladrão, um pensador livre, um empreendedor, entre outros significados. Do ponto de vista do partido, qualquer pessoa que concorde conosco e nos apoie, será um pirata. (Português, masculino, 26 anos, entrevista) $)^{6}$

Uma prática pirata é aquela que favorece toda a sociedade: uso do software livre por autoridades, mais transparência governamental, incentivo à cultura livre etc. Atitudes piratas não surgem unicamente dos piratas. A diferença é que quem não é pirata não as toma como causa, apenas como uma medida dentre outras, boa parte delas contrárias à população. (Brasileiro, masculino, 22 anos, inquérito $)^{7}$

Pirata é alguém que, ao defender um princípio basilar de livre compartilhamento de conhecimento e cultura, define-se eminentemente contra-autoritário no exercício das relações em sociedade, seja na relação com o Estado, seja na relação com entidades privadas. Daí decorre que, um pirata é alguém que defende direitos civis individuais, privacidade individual, transparência pública e empoderamento das pessoas que se valem de livre conhecimento, pessoas essas que passam a exercer de forma mais direta a dinâmica coletiva da sociedade, seja nas relações privadas, seja no exercício da democracia. (Brasileiro, masculino, 28 anos, inquérito) ${ }^{8}$

No campo da visibilidade, o exercício dos piratas aproxima-se de uma prática contrapropagandística, como um recurso exaustivo e repetitivo da sua vida 
${ }^{9}$ Cf. figura 3 e 4 deste capítulo. Cf. PIRATENPARTEI, s.d. publicitária. Em termos gerais, o objetivo desse tipo de ação é promover as próprias ideologias a partir do combate das teses dos adversários de modo persuasivo em que a atenção social é atraída por mecanismos que visam "desmontar" e colocar em contradição as ideias defendidas pela oposição (DOMENACH, 1963). Essa tentativa de desestruturação dos modelos tradicionais da publicidade política, embora seja feita a partir de uma imitação sistêmica das formas clássicas utilizadas em campanhas eleitorais, é melhor notada na difusão de imagens, palavras e temas que não integram de modo explícito o universo sígnico dos partidos dominantes.

Um dos cartazes da campanha eleitoral do Partido Pirata da Alemanha utilizado nas eleições nacionais de 2013 expressa o descontentamento com a política de habitação e os altos preços dos aluguéis praticados no país. Em letras garrafais lê-se: "Die scheiss Mieten sind zu hoch"; em tradução livre, algo como: "O aluguel está alto pra caralho". Em outro pôster a figura engravatada de um homem, uma das únicas da campanha, faz companhia ao letreiro Vater Vater Kind (Pai, pai, filho) e serve para divulgar as políticas de igualdade para todos os tipos de organização familiar. Os piratas abusam um pouco mais da estética publicitária. As políticas de diversidade cultural e de gênero são divulgadas com adesivos que misturam a logomarca do Partido com símbolos informáticos, grafismos multicoloridos e palavras que identificam órgãos sexuais. Juntos simbolizam a fusão da política, da tecnologia, do amor e da diversidade sexual. A luta pela liberdade do livre consumo da cannabis vai divulgada em pacotes de papel para enrolar o tabaco9.
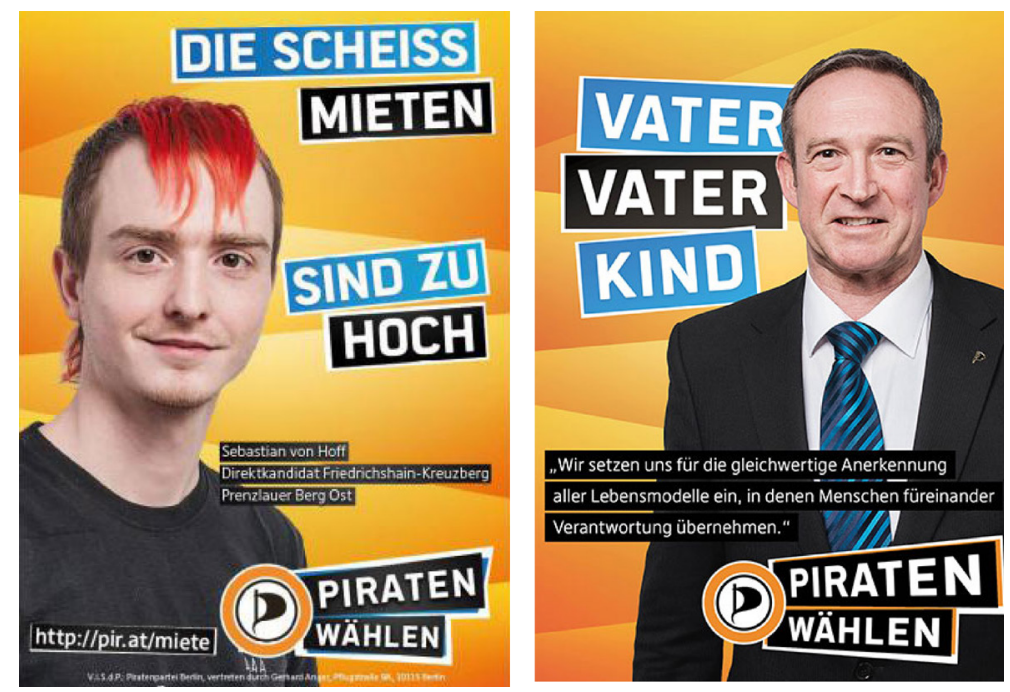

Figura 3: Cartazes da campanha política do Piratpartei/Divulgação (PIRATENPARTEI, 2013).
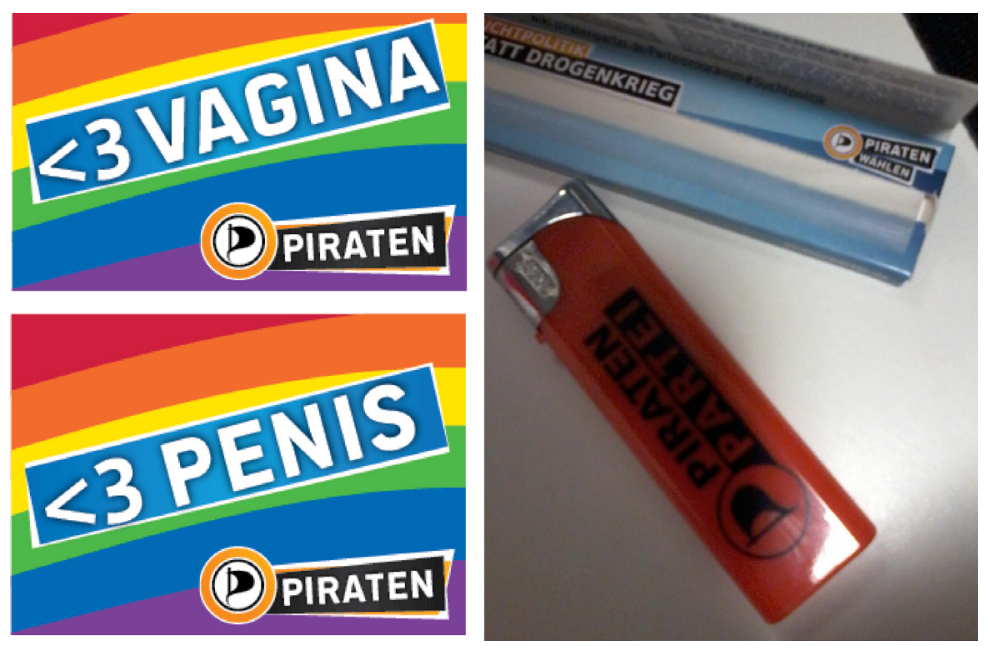

Figura 4: Material de campanha do Piratpartien (direita: Piratpartien, 2013, esquerda foto de Rodrigo Saturnino, 2013) 
10 "Hahahaha... Nien" é a onomatopeia de uma risada jocosa seguida de uma interjeição para exprimir uma rejeição. A expressão pode ser traduzida para o português como: "Hahahaha... Não".

"Echt Jetzt?!" é uma expressão utilizada para por em dúvida uma afirmação. $\mathrm{Na}$ tradução para o português de Portugal seria algo como "Ah, sério?" ou "Tás a gozar?", enquanto para o português do Brasil seria "Jura?", e ainda, em inglês, "Oh, really?".

${ }^{11}$ Cf. figura 5 deste capítulo.

${ }^{12}$ Cf. figura 6 deste capítulo.
Outra forma utilizada pelos piratas da Alemanha para estabelecer a interação simbólica com os transeuntes durante os períodos de campanha eleitoral é feita pela criação de um diálogo imaginário com a propaganda da oposição. Mensagens de cartazes rivais são replicadas por meio de um pequeno letreiro, fixado abaixo do pôster oponente. A política do adversário é contestada através de sentenças irônicas a fim de ridicularizar as promessas dos partidos tradicionais. Frases do tipo "Hahahaha... Nien" ou "Echt Jetzt?!"10, aparentemente inofensivas, servem de agente de escárnio para liberar o riso desdenhoso (Domenach, 1963). Ridicularizada também foi a imagem de Angela Merkel. Para criticar as políticas de vigilância do governo da Chanceler, a cabeça arrancada dá lugar a uma câmera de filmar ${ }^{11}$.

Ações semelhantes são encontradas na publicidade dos Piratas do Brasil. O recurso ao duplo sentido, complementa a ação de bricolagem que realizam. O texto Chega de política falsificada. Seja original. Seja Pirata!, reitera a função estratégica de inversão dos valores que a antífrase, enquanto tropo, permite ${ }^{12}$. A intenção sarcástica da ironia, de modo geral, utiliza o carácter ambíguo dos sentidos tornandose, menos em um procedimento estilístico e mais em um método denotativo (BARTHES, 1990) que busca no conhecimento cultural do interlocutor que lê, referenciais predecessores que contribuem para liberar o poder da sua mensagem. Nesse sentido, grande parte da ação midiática do MPP baseia-se nos mapas culturais estabelecidos anteriormente sobre a imagem do pirata, sua função e as práticas que dele decorrem de modo a romper por vias antagonizantes os sentidos dogmáticos. Aqui, a linguagem é um recurso seminal que ultrapassa um pouco mais o caráter simplório da retórica do palanque para transformar-se em projeção perturbadora da estrutura da ordem.
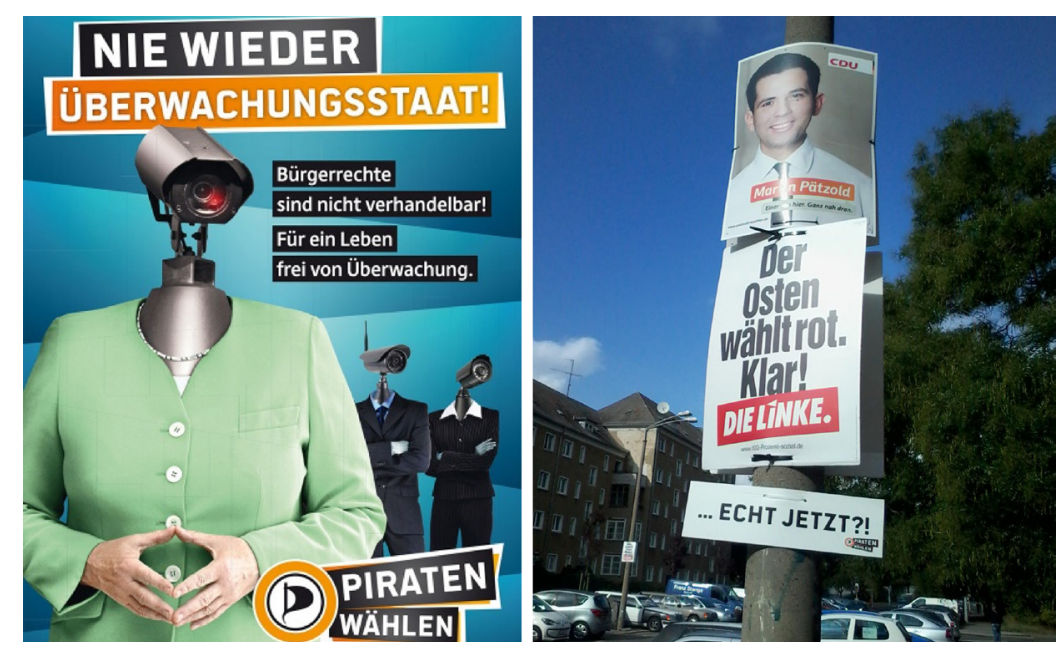

Figura 5: Direita: Cartaz da campanha pirata em Berlim/ Divulgação (PIRATENPARTEI, 2013). Esquerda: Letreiro/Arquivo pessoal (imagem Rodrigo Saturnino, 2013).

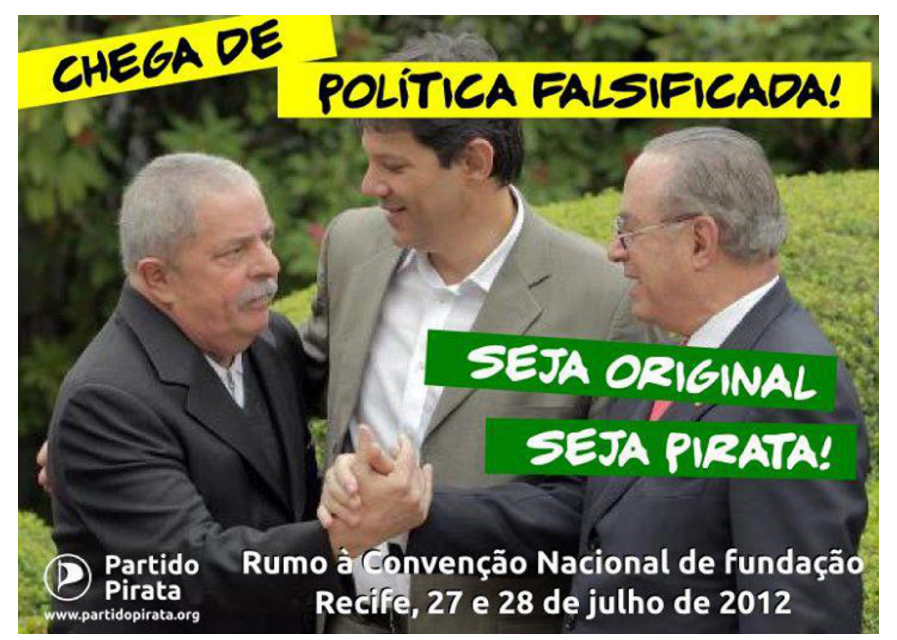

Figura 6: Flyer digital do Partido Pirata do Brasil/Divulgação (PARTIDO PIRATA DO BRASIL, 2012). 
Tal conjunto de práticas materializa uma estratégia auferida por linguagens próprias intencionadas em divulgar a qualidade das suas identidades sociais e, sobretudo, em hostilizar os princípios fundacionais do sistema. Uma transgressão que utiliza, seguindo as contribuições de autores como Durand (1974) e Barthes (1990), a retórica do visual como método apoiado na liberdade estilística que a publicidade permite e, assim, distingue uma forma excepcional de existência política. Trata-se de um movimento ostensivo de integração, em suas diversas instâncias, do projeto de vida desses atores em que as formas de resistência se agitam por estratégias e estruturas enunciativas emitidas por ensaios contestatórios às figuras do poder dominante. São recursos de ancoragem identitária assentes na saturação e no antagonismo da diferença como um porto concreto de subversão das lógicas sociais que subjugam os comportamentos laicos e os modos dessacralizados de existir. O jogo de sentidos entre o "falso" e "original" elaborado pela indústria do entretenimento e das grandes marcas inverte-se para o campo da política, tornando-se um instrumento implícito de negações e oposições. Uma estratégia performática e, por vezes, excessiva, que abusa do caricatural a fim de "singularizar, através de uma aposta numa estética que assinala sua presença no mundo e que, nos seus excessos neo-barrocos, se traduz em manifesto de existência dos seus protagonistas" (FERREIRA, 2011, p. 121).

\section{Conclusão: a festa pirata}

A julgar pelo contexto da crise oferecida pela digitalização da informação (GARCIA, 2006; MACHUCO ROSA, 2006; BOYLE, 2008; SCHILLER, 1999, 2007; BRANCO, 2011; BOLAÑO, 2000, DANTAS, 1999) é imperativo dizer que o MPP não figura como uma solução conflitual. Ao contrário, faz cintilar o próprio conflito no interior do capitalismo informacional. Sem dúvida, o exemplo sueco marcou o processo de transição do ativismo civil para a formação de estratégias políticas permanentes de combate à criminalização de algumas práticas de partilha da informação pela internet (HINTIKKA, 2006; ANDERSSON, 2011). Além disso, a politização do discurso reorientou a agenda pública a respeito da utilização irrestrita da lei nos casos onde se alegava a violação de direitos autorais. Ao retirarem a exclusividade do fator legal como recurso operatório e decisivo, a questão deixou de ser um problema da lei tornando-se, decisivamente, de ordem sóciopolítica. Nesse caso, não bastaria remediar os casos de violação do copyright com intervenção jurídica sem antes examinar, entre outras coisas, o grau de infração dos direitos civis - como o da privacidade - pela simples aplicação da norma em defesa dos interesses privados (DAHLBERG, 2011).

O surgimento do MPP ajuda-nos a pensar na hermenêutica desafiadora que o seu projeto representa no percurso de reflexão sobre a legitimidade da lei, a começar pela arbitrariedade que a norma estabelece com sua lógica da distinção. De fato, a imagem bucólica dos piratas marítimos, de certa forma, desapareceu das águas. $\mathrm{E}$, apesar da discursividade pejorativa do termo, a pirataria também foi utilizada como figura arquétipa de resistência social. A imagem mitológica do pirata foi celebrada como símbolo poético e subversivo da ordem política dominante. 0 caráter clandestino e aventureiro do pirata inspirou diversas leituras qualificativas acerca da sua função no campo das lutas sociais. Os textos de Pessoa (1915), Lapouge (1998), Bey (1991), Machado (2013) e tantos outros inflamaram a figura refrigerada do pirata ao exaltá-la como um dos símbolos utópicos de superação das crises narrativas dos poderes instalados. Os relatos históricos da dinâmica de vida dos piratas fortaleceram visões mais politizadas acerca de suas práticas. Rediker (2004), que faz coro com outros autores, ao escrever Villains of all Nations salientou o caráter solidário presente nas ações libertárias dos piratas no século XVIII. Segundo o autor, ao acolherem escravos africanos a bordo de seus navios, libertavam-nos e, com isso, implantavam um sistema próprio e mais igualitário na distribuição de recursos. Nessa perspectiva, a pirataria é admitida como uma 
oposição temporária que se transforma em condição permanente. No rastro da história da marinha, os piratas eram vistos por um olhar ressentido, pois, de certa forma, criaram outra força naval com um funcionamento mais plausível, possivelmente mais recíproco, democrático e libertário.

Enquanto figura emblemática, a imagem do pirata é proibida. Ela é o avesso da artificialidade de um mundo organizado ao redor da moral do dinheiro. Nas sociedades ordenadas pela razão cultivada, é considerada ameaça, e não é bemvinda. Como símbolo de ruptura, faz contraponto aos constrangimentos legais que controlam coercivamente a barbárie interna e protegem toda a moralidade cartesiana. A incorporação da figura do pirata pelo MPP, apesar de aparentar uma atitude bucólica, indicia a ousadia das suas premissas e faz lembrar o caráter político do détournement como instrumento situacionista de dissidência (DEBORD; WOLMAM, 2006). A busca por uma convergência ontológica da semântica iniciada pelo Piratbyrån reverbera, de forma sólida, na prática discursiva desses atores. Em vez de rejeitarem ou destruírem a identidade, assumiram o risco de substituir a morfologia obsoleta por um significado antagônico ao seu sentido original para dele usufruir. É nesse sentido que a sua ação incentiva a reflexão sobre a episteme política que está imbricada na sua representação.

Do mesmo modo em que os contextos de coerção da lei e de subjetivação dos indivíduos a que os piratas marítimos estavam subjugados representavam um contexto idealizado para a sua resistência civil, o deslocamento da pirataria para novos campos de disputa de poder, como o da informação digital, serve também como pressuposto para o exercício de uma prática crítica em relação à violência instrumental dos dispositivos legais e protecionistas criados para punir os supostos delitos cometidos contra a propriedade intelectual. Seguindo tal raciocínio, os piratas admitem que a força coercitiva da legislação dos direitos autorais e de patentes solicita uma ação política que se engaje na luta para impedir a privatização do bem comum.

Não é conclusivo atribuir à ação do MPP um exemplo típico daquilo que Debord e Wolmam (2006) defenderam a respeito da prática que propuseram em finais da década de 1950. Mas também não está distante, a ideia de que conduziram o termo a um outro conjunto de significados com uma nova dimensão e novo efeito social. Através do choque, da ironia, da sátira e da substituição, utilizam o rótulo a partir de um ethos próprio. Seguindo a proposta de Lessig (2008) e Garcia e Silva (2012), em um tempo de intertextualidades criativas, a metáfora perde o seu valor como marcador epistêmico de um estigma, passando a ser utilizada em forma de pastiche para demarcar uma ideologia que desconstrói para reconstruir.

Sem dúvida, a tônica dessa premissa reaviva o debate ideológico e utópico em relação à tomada de poder por novos movimentos sociais. As experiências cotidianas dos partidos políticos tradicionais pulverizam dúvidas em relação à atuação das minorias partidárias. No entanto, o discurso da crise renova-se pelo vigor de suas certezas. Na concepção de Ricoeur (1991), a ideologia é um fator de integração que age como mediador simbólico na ação social de acordo com a necessidade de um determinado grupo preservar ou fortalecer sua identidade e sua forma de representação. Ao mesmo tempo em que a ideologia constitui a imagem de si mesma, do outro lado a utopia pode também ser interpretada como uma implicação saudavelmente necessária para a criação de alternativas aos modelos hegemônicos. O seu caráter disruptivo e transformador ensina que existe entre a crise e a utopia uma relação profunda. Como salientou Serra (1998, p. 27-29), "toda utopia é simultaneamente, quer um sintoma da crise do viver de um certo mundo, quer a forma imaginária [...] de superação dessa crise". Para além das metáforas, a qualidade ideológica defendida pelos piratas, se não apresenta uma solução imediata, ao menos reatualiza o imaginário social acerca da função antagônica da utopia e da ideologia: de subversão, de destruição da 
realidade existente, no primeiro caso, e de conservação, de confirmação da realidade existente, no segundo.

Não há garantias de que os Partidos Piratas, como movimento social ou partido político, consigam ultrapassar a sofisticação das parcerias já travadas no núcleo das políticas internacionais da informação, da cultura e do conhecimento. Tampouco de que conseguirão, finalmente, transformar a democracia em um projeto menos opaco e mais realizável, permanecendo isentos do processo de cooptação e homogeneização que caracteriza a tradição política ocidental. Os conflitos internos que experimentam, o crescimento silencioso e a política catchall que passou a vigorar no seu programa não profetizam o seu fim. Ao contrário, parecem adiantar os novos desafios que se apresentam ao Partido Pirata na concretização de seus interesses e, por conseguinte, em sua afirmação enquanto movimento global comprometido a questionar a normatividade dos fundamentos políticos da regulação da informação.

\section{Referências Bibliográficas}

ANDERSSON, J. The origins and impacts of the swedish file-sharing movement: a case study. Journal of Peer Production. Disponível em: <http://peerproduction. net/issues/issue-0/peer-reviewed-papers/the-origins-and-impacts-of-swedishfilesharing>. Acesso em: 11 nov. 2012.

BARTHES, R. O óbvio e o obtuso. Rio de Janeiro: Nova Fronteira, 1990.

BECKER, H. S. Outsiders: estudos de sociologia do desvio. Rio de Janeiro: Zahar, 2008.

BELISÁRIO, A.; TARIN, B. (Orgs.). Copyfight: pirataria e cultura livre. Rio de Janeiro: Azougue Editorial, 2013.

BEY, H. T.A.Z.: The temporary autonomous zone, ontological anarchy, poetic terrorism. Disponível em: <http://hermetic.com/bey/taz3.html\#labelTAZ>. Acesso em: 11 nov. 2012.

BOLAÑO, C. Indústria cultural, informação e capitalismo. São Paulo: Editora HucitecEditora Pólis, 2000.

BOYLE, J. The public domain: enclosing the commons of the mind. Londres: Yale University Press, 2008.

BOURDIEU, P. A economia das trocas simbólicas. São Paulo: Perspectiva, 2009. . O poder simbólico. Lisboa: Difel, 1989

BRANCO, S. O domínio público no direito autoral brasileiro: uma obra em domínio público. Rio de Janeiro: Lumen Juris, 2011.

CASTELLS, M. A galáxia da internet: reflexões sobre a internet, negócios e sociedade. 2. ed. Lisboa: Fundação Calouste Gulbenkian, 2007.

CASTELLS, M.; CARDOSO, G. (Orgs.). Piracy cultures: how a growing portion of the global population is building media relationships through alternate channels of obtaining content. Indiana: Xlibris, 2013.

DAHLBERG, L. Pirates, partisans, and politico-juridical space. Law and Literature, v. 23, n. 2, Summer, p. 262-281, 2011. 
DANTAS, M. Capitalismo na era das redes: trabalho, informação, valor no ciclo da comunicação produtiva. In: LASTRES, H.; ALBAGLI, S. (Orgs.). Informação e globalização na era do conhecimento. Rio de Janeiro: Editora Campus, p. 216161, 1999.

DEBORD, G.; WOLMAN, G. J. A user's guide to détournement. In: KNABB, K. (Ed.). Situationist International Anthology. Berkeley: Bureau of Public Secrets, p. 31-43, 2006.

DECHERNEY, P. Hollywood's copyright wars: from Edison to the internet. Nova York: Columbia University Press, 2012.

DOMENACH, J. A propaganda política. 2. ed., São Paulo: Difel, 1963.

DURAND, J. Retórica e imagem publicitária. In: METZ, C. et al. A análise das imagens. Petropólis: Vozes: 1974.

DURAND, R.; VERGNE, J. The Pirate organization: lessons from the fringes of capitalism. Boston/Massachusetts: Harvard Business School Publishing Corporation, 2013.

ERLINGSSON, G.; PERSSON, M. The Swedish Pirate Party and the 2009 European Parliament Election: protest or issue voting? Politics, v. 31, n. 2, p.121-128, 2010.

FERREIRA, V. S. O "jovem radical" contemporâneo: novos sentidos de um qualificativo juvenil. Crítica e Sociedade: revista de cultura política, v.1, n. 2, p.107-127, 2011.

FLOCH, J. Identités visuelles. Paris: PUF, 1995.

GANTZ, J.; ROCHESTER, J. B. Pirates of the digital millennium: how the intellectual property wars damage our personal freedoms, our jobs, and the world economy. Nova Jersey: FT Press, 2005.

GARCIA, J. L. Biotecnologia e biocapitalismo global. Análise Social, v. XLI, n. 181, p. 981-1009, 2006.

GARCIA, J. L.; SILVA, P. D. YouTubers as satirists: humour and remix in online video. eJournal of eDemocracy and Open Government - JeDEM, v. 4, n. 1, p. 89-114, 2012.

GOFFMAN, E. Estigma: notas sobre a manipulação da identidade deteriorada. 4. ed. Rio de Janeiro: Guanabara Kooganm, 1998

GORZ, A. O imaterial: conhecimento, valor e capital. São Paulo: Annablume, 2005.

HIGGINS, G. E.; MARCUM, C. D. Digital piracy: an integrated theoretical approach. Durham: Carolina Academic Press, 2011.

HINTIKKA, K. A. Pirates in politics - Internet piracy as individualised politics. 2006, Disponível em: <http://www.edemocracy.uta.fi/eng/haefile.php?f=113>. Acesso em: 11 nov. 2012.

JOHNS, A. Piracy: the intellectual property wars from Gutenberg to Gates. Chicago/ Londres: University of Chicago Press, 2009.

KERNFELD, B. D. Pop song piracy: disobedient music distribution since 1929. Chicago/Londres: University of Chicago Press, 2011.

LAPOUGE, G. Os piratas: piratas, flibusteiros, bucaneiros e outros párias do mar. 
Lisboa: Antígona, 1998.

LEMOS, R. Direito, tecnologia e cultura. Rio de Janeiro: Editora FGV, 2005.

LESSIG, L. Free culture: the nature and future of creativity. Nova York: Penguin Press, 2004.

. Remix. Making art and commerce thrive in the hybrid economy. Londres: Bloomsbury Academic, 2008.

LÉVI-STRAUSS, C. Antropologia estrutural. 6. ed. Rio de Janeiro: Tempo Brasileiro, 2003.

LI, M. The Pirate Party and the Pirate Bay: how the Pirate Bay influences Sweden and International Copyright Relations. Pace International Law Review, v. 21, n. 1, p. 281-307, 2009.

LIMA, R. C. P. Sociologia do desvio e interacionismo. Tempo Social, v.13, n. 1, p. 185-201, 2001.

MACHADO, J. Sonho pirata ou realidade 2.0. In: BELISÁRIO, A.; TARIN, B. (Orgs.). Copyfight: pirataria e cultura livre. Rio de Janeiro: Azougue Editorial, p.31-40, 2013.

MACHUCO ROSA, A. Cinco lições sobre comunicação, redes e tecnologias da informação: da cibernética ao copyright. Lisboa: Vega, 2006.

MASON, M. The pirate's dilemma: how youth culture is reinventing capitalism. Nova York: Free Press, 2009.

MIEGEL, F.; OLSSON, T. From pirates to politician: the story of the swedish file sharers who became a political party. In: CARPENTIER, N. et al. (Orgs.). Democracy, journalism and technology: new developments in an enlarged Europe. Estonia: Tartu Publisher Press, p. 203-217, 2008.

PANEBIANCO, A. Modelos de partido: organização e poder nos partidos políticos. São Paulo: Martins Fontes, 2005.

PARTIDO PIRATA DO BRASIL. Fotos do Partido Pirata do Brasil. Facebook. 2012, Disponível em: <https://www.facebook.com/photo.php?fbid=4611984539076 69\&set=pb.180044272023090.2207520000.1381782005.\&type=3\&theater $>$. Acesso em: 13 maio 2013.

PESSOA, F. Ode Marítima. Revista Orpheu, v. 1, n. 2, 1915. Disponível em: <http:// www3.universia.com.br/conteudo/literatura/Orpheu_n2_de_alvaro_de_ campos.pdf >. Acesso em: 17 jul. 2013.

PIRATENPARTEl. BE: Wahlkampf/2013/Material. Disponível em: <http://wiki. piratenpartei.de/BE:Wahlkampf/2013/Material>. Acesso em: 12 mar. 2013.

PIRATENPARTEI. Plakat/Vorlage. Disponível em: <http://wiki.piratenpartei.de/ Plakat/Vorlage>. Acesso em: 14 abr. 2013.

PIRATENPARTEI. Wahlen/Bund/2013/Plakatmotive. 2013. Disponível em: <http:// en.wikipedia.org/wiki/File:Piratpartiet.svg>. Acesso em: 12 mar. 2013.

PIRATPARTIET. European pirate platform 2009. Disponível em: <http://www. piratpartiet.se/nyheter/european_pirate_platform_2009>. Acesso em: 02 fev. 2012. 
POLLNER, M. Mundane reason: reality in everyday and sociological discourse. Cambridge: Cambridge University Press, 1987.

POSTIGO, H. The digital rights movement: the role of technology in subverting digital copyright. Cambridge/Londres: The MIT Press, 2012.

REDIKER, M. Villains of all nations: atlantics pirates in the golden age. Boston Massachusetts: Beacon Press, 2004.

RICOEUR, P. Ideologia e utopia. Lisboa: Edições 70, 1991.

SCHILLER, D. Digital capitalism: networking the global market system. Cambridge/ Massachusetts/Londres: The MIT Press, 1999.

SCHILLER, D. How to think about information. Urbana/Chicago: University of Illinois Press, 2007.

SCHILLING, F.; MIYASHIRO, S. G. Como incluir? O debate sobre o preconceito e o estigma. Educação e Pesquisa, v. 34, n. 2, p. 243-254, 2008.

SCHWEIDLER, C.; CONSTANZA-CHOCK, S. Piracy. In: AMBROSI, A.; PEUGEOT, V. PIMIENTA, D. (Orgs.). Word matters: multicultural perspectives on information societies. Disponível em: <http://vecam.org/article694.html?lang=en>. Acesso em: 23 nov. 2013.

SERRA, P. A informação como utopia. Covilhã: Universidade da Beira Interior, 1998.

STALLMAN, R. M. Frees software, free society: selected essays of Richard M. Stallman. Boston: GNU Press, 2002.

STRANGELOVE, M. The empire of mind: digital piracy and the anti-capitalist movement. Toronto: University of Toronto Press, 2005.

TORRENT FREAK. German Piraty Party on course to election win. Disponível em: <http://torrentfreak.com/german-pirate-party-on-course-to-election -win-110820/>. Acesso em: 13 maio 2013.

VAIDHYANATHAN, S. Copyrights and copywrongs: the rise of intellectual property and how it threatens creativity. Nova York: New York University Press, 2003.

VERGNE, J. The pirate and the capitalist: A love story? Policy, v. 29, n. 3, Spring, p. 3-9, 2013.

WIKIPEDIA. File:Piratpartiet.svg. Disponível em: <http://en.wikipedia.org/wiki/ File:Piratpartiet.svg>. Acesso em: 12 mar. 2013. 